\title{
From Antipsychotic-related Hyperprolactinemia to Klinefelter Syndrome: Taking the Patient as a Whole
}

Raya Almazrouei, Rozana Ramli, Emma Hatfield, Karim Meeran, Florian Wernig Imperial College Healthcare NHS Trust

\section{Introduction:}

- Klinefelter syndrome (KS), 47,XXY, occurs in 150 per 100,000 live born males on neonatal karyotyping.

- British and Swedish studies estimate a prevalence of KS of 11.9 per 100,000 and 23.1 per 100,000 males respectively

- It seems that only $25-40 \%$ of the pool of KS are ever diagnosed, and only about $10 \%$ of these are diagnosed during childhood and adolescent years, while the bulk of patients are diagnosed during adulthood, typically in the course of a fertility workup.

- There is no universal agreement on the necessary clinical signs or stigmata that should lead to karyotyping.

- The diagnosis of a male with KS rests on clinical appearance coupled with a karyotype of 47,XXY or mosaics form.

- The cardinal stigmata include small testes (which are present in virtually all KS), hypergonadotropic hypogonadism, gynecomastia, learning difficulties and infertility

- Many other conditions can be associated with KS like diabetes mellitus, dyslipedemia, psychiatric disorder, mitral valve prolapse, breast cancer and extragonadal germ cell tumors.

\section{Investigations:}

- Blood results showed anemia with hormonal panel suggestive of primary hypogonadism (Table 1). Hyperprolactinemia was felt to be secondary to antipsychotics and no pituitary MRI was carried out. Rest of the pituitary hormonal panel was within normal range.

- After confirmation with another set, karyotyping was requested and revealed 47,XXY consistent with Klinefelter syndrome.

- DEXA scan revealed osteopenia of the L2-L4 segment (T-score -1.2) and normal density of the femora (T-score 0.6 ).

\section{Management:}

- Patient was started on Transdermal testosterone replacement with significant improvement in haemoglobin level (Table 1).

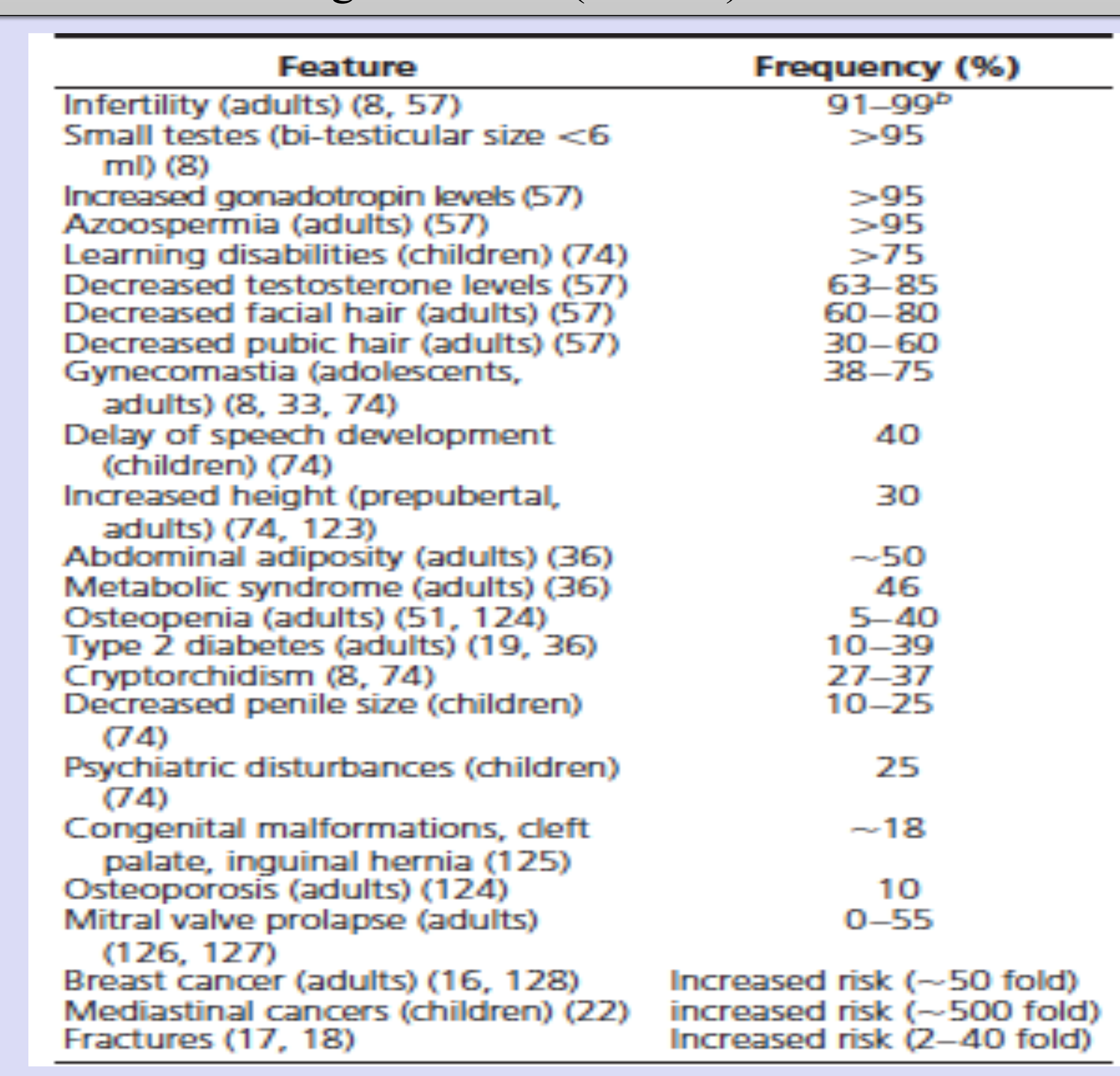

Table 2: Abnormalities associated with KS and their tentative frequencies. Adapted from Ref 1 .

\section{Discussion:}

This case illustrates several points:

- Firstly, the diagnosis of Klinefelter syndrome may be missed due to very variable phenotypical presentations. Many conditions and different co-morbidities can be associated with KS (Table 2).

- Knowledge about the genotype-phenotype relation in KS is limited. Genetic mechanisms related to the $\mathrm{X}$ chromosome as well as the androgen receptor have been evaluated for a possible impact on the phenotype in KS. These genetic mechanisms include the parental origin of the supernumerary X chromosome, the pattern of $\mathrm{X}$ chromosome inactivation and the androgen receptor CAG repeat length (Figure 1).

- Secondly, testosterone deficiency can be a cause of unexplained anaemia (Table $3)$.

Thirdly, patients with Klinefelter syndrome can develop thromboembolic disease (4 to 8-fold) and are at risk of psychosis, autism and ADHD.

\section{References:}

1. Groth et al. Klinefelter Syndrome-A Clinical Update .J Clin Endocrinol Metab, January 2013, 98(1):20-30.

2. Gravholt et al. Klinefelter syndrome - integrating genetics, neuropsychology and endocrinology. Endocrine reviews, August 2018, 39(4): 389-423.

\section{Case History:}

- A 59 year old man was referred to our endocrine service for persistently elevated prolactin levels in the range from 1477 to 1972 milliunit/L [60-300] for many years with negative macroprolactin.

- He did not report any headache, visual disturbance or galactorrhoea.

- He was diagnosed with schizophrenia in 1994 and was tried on different antiphychotic drugs until established on a combination of Amisulpride and Clozapine 11 years later.

- Further history revealed that he had been diagnosed with normocytic normochromic anaemia for which no cause had been identified.

- On direct questioning, the patient reported erectile dysfunction and loss of morning erections. He had not been sexually active since 1993 .

- In addition, he had a history of un-provoked deep venous thrombosis and pulmonary embolism, hyperlipidaemia and diabetes mellitus type 2.

\section{Examination:}

- Physical examination showed a pale and tall man with central obesity and scanty body and facial hair.

- There was no gynaecomastia on breast examination.

- Testicular examination was not performed initially.

\begin{tabular}{|l|l|l|}
\hline Table 1 & $\begin{array}{l}\text { Before Testosterone } \\
\text { replacement (On Diagnosis) }\end{array}$ & $\begin{array}{l}\text { After Testosterone } \\
\text { replacement }\end{array}$ \\
\hline Haemoglobin (130-169) g/L & 118 & 132 \\
\hline LH (2-12) IU/L & 11.5 & 5.4 \\
\hline FSH (1.7-8) IU/L & 28.6 & 17.1 \\
\hline Testosterone (10-30) nmol/L & 1.7 & 11.3 \\
\hline $\begin{array}{l}\text { Prolactin [60-300] milliunit/L/ } \\
\text { Negative macroprolactin }\end{array}$ & 1199 & 1961 \\
\hline
\end{tabular}

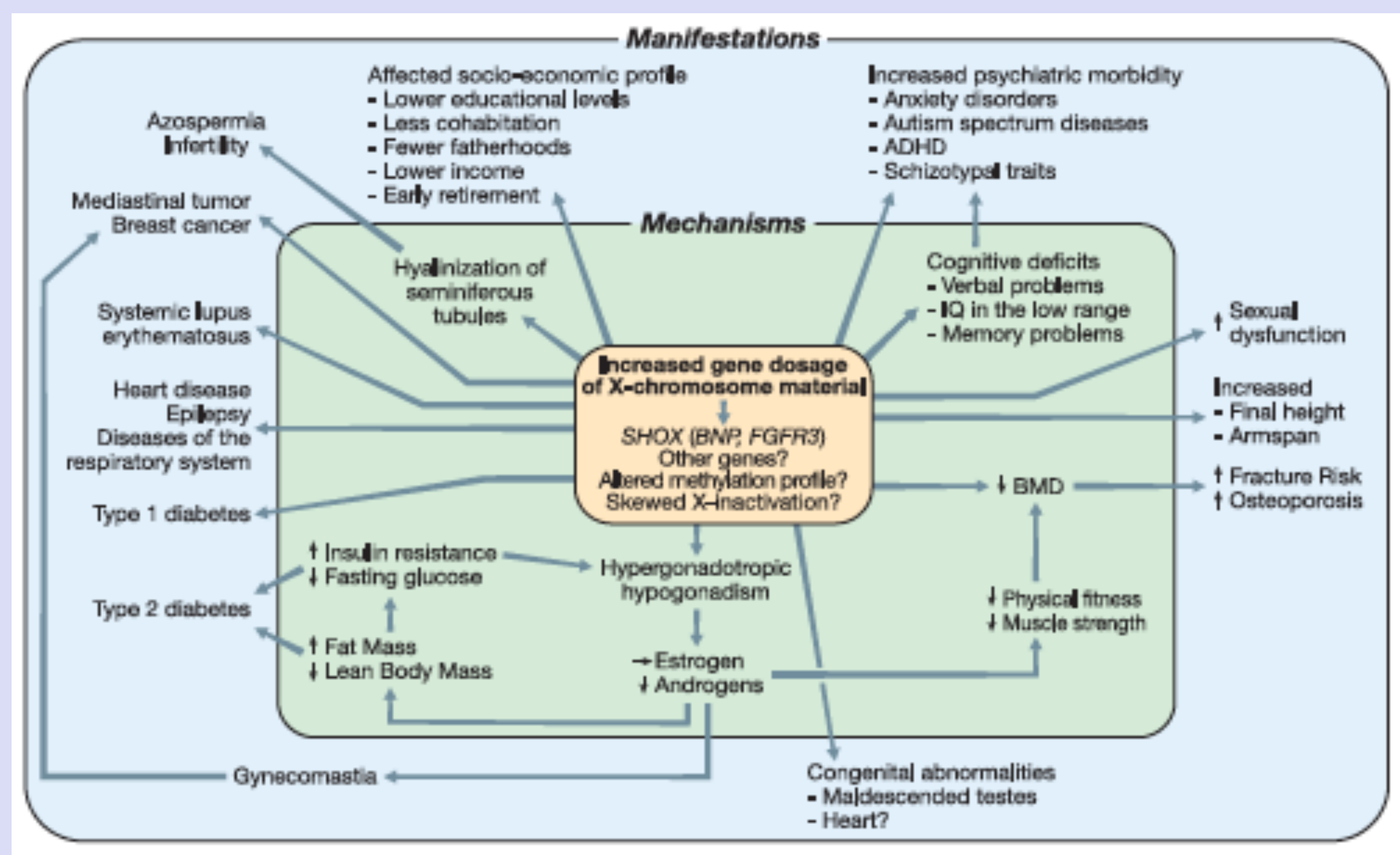

Figure 1: The effect of increased dosage of genes on the X-chromosome (and possibly other genetic mechanisms) Adapted from Ref 1

\begin{tabular}{|l|l|}
\hline Table 3 & Hypothesis/Evidence \\
\hline Thrombosis & $\begin{array}{l}\text { Vascular abnormalities and/or worse risk profile for venous } \\
\text { thrombosis. } \\
\text { Abnormalities in fibrinolysis with increased plasma activity } \\
\text { of plasminogen activator inhibitor-1 (PAI-1). } \\
\text { Increased activity of factor VIII. } \\
\text { Platelet hyperaggregability. }\end{array}$ \\
\hline Anemia & $\begin{array}{l}\text { Hypogonadal state leads to increase plasma concentration of } \\
\text { hepcidin and decrease cellular expression of ferroportin. }\end{array}$ \\
\hline Schizophrenia & $\begin{array}{l}\text { A review of studies of male psychiatric inpatients from the } \\
1960 \text { s to the 1990s found a frequency of KS ranging from 0 } \\
\text { to 4.8\% (mean, 0.8\%) among schizophrenic patients, a 4- to } \\
5 \text {-fold increase compared with the prevalence of KS in the } \\
\text { general population. }\end{array}$ \\
\hline
\end{tabular}

